\title{
Waters without borders: Transboundary water governance and the role of the 'transdisciplinary individual' in Southern Africa
}

\author{
IM Jacobs* and S Nienaber \\ Natural Resources and the Environment, Council for Scientific and Industrial Research (CSIR), PO Box 395, \\ Pretoria, 0001, South Africa
}

\begin{abstract}
Water resources in the Southern African Development Community (SADC) play an intrinsic role in regional development. As a result, water is a highly sensitive issue, complex to understand and demanding to govern, in terms of effective and equitable use and distribution. Growing awareness of the complex challenges facing water and the cross-cutting impacts that these challenges have on the region has led to the recognition that these challenges demand more integrated levels of ingenuity and expertise from a diverse set of actors working in a transdisciplinary manner.

In response to these realisations a significant body of work has emerged that attempts to determine the criteria of a transdisciplinary approach and how it can be operationalised. This has led to significant progress in gaining an understanding of 'transdisciplinary team' approaches. These transdisciplinary teams have tended to work at the localised or project level of problem response. However, despite this progress, little work has been done on how to upscale transdisciplinary research and practice to the regional level. This is a significant gap given the fact that the source of many complex problems lies at the regional level even if the effects of these problems are localised. Also, little has been done to try to move the transdisciplinary discourse beyond the transdisciplinary team in order to understand how to groom and develop "transdisciplinary individuals' who have the competence and talent to rise to the complex challenge of fostering regional economic development, of which water is a key component.

Given this context, this paper builds on the existing literature in transdisciplinarity and its different conceptualisations in relation to water in Southern Africa. Firstly, it interrogates the cross-cutting role of water in regional socio-economic development in the SADC region. Secondly, it examines the need for transdisciplinary responses to regional socio-economic development. Thirdly, this paper strives to make a valuable contribution to knowledge in that it attempts to take the transdisciplinary discourse beyond 'the team' model to examine the role of the individual and the internalisation of transdisciplinarity as a mindset beyond collective models. In this regard, the paper emphasises the need for 'transdisciplinary individuals' to rise to the complex challenge of regional integration, and particularly, the role of the younger professionals in this process.
\end{abstract}

Keywords: transboundary, governance, transdisciplinarity, social science, SADC, complexity, global change, regional development

\section{Introduction}

The Southern African Development Community (SADC) has always grappled with the challenge of water scarcity. As a result, a high expectation has traditionally been placed on the scientific community to produce technical supply-driven solutions to reduce the perceived and associated vulnerabilities and their impact on the region's 258 million inhabitants. However, shared water resources in the region are highly sensitive and complex to understand, govern, effectively use and fairly distribute. This complexity is multi-dimensional. Firstly, the complex and interconnected characteristics of international river basins liken them to complex adaptive systems (CAS), comprising both living and non-living elements, i.e., infrastructure, roads, ecosystems and human communities that interact with each other in dynamic and non-linear ways. Secondly, the challenges facing the resource and the people who depend on it have been equally complex. Particularly, emerging global and regional pressures such as climate change,

This paper was originally presented at the Water Research Commission 40-Year Celebration Conference, Kempton Park,

31 August - 1 September 2011.

* To whom all correspondence should be addressed.

证 +27 84 674-2470; fax: +27 12 331-2565; e-mail: IngaJacobs30@gmail.com population growth, urbanisation and capacity constraints, have raised concerns about whether existing technical solutions alone are adequate to deal with the complexity of these challenges. Some of these water-related security challenges have been around for decades while others are new or emerging issues. In response to these challenges, a growing body of literature has emphasised the need for more integrated levels of ingenuity and expertise from a diverse set of disciplines and actors. This sentiment has been echoed in several studies over the past 3 decades in the examination and application of concepts such as integrated water resource management (IWRM), the Public Participation Process (PPP), integrated natural resource management (INRM), and the sector-wide approach, to mention a few (GWP-TAC, 2000; King et al., 2003; Sayer and Campbell, 2004).

The growing international consensus on the need to collaborate across boundaries is regarded as the genesis of collective action at the regional level, and provides compelling evidence of the emergence of beyond-border cooperation to solve the many water challenges facing the region (GWP, 2010). Today, it is well-known that cooperative arrangements are increasingly moving away from a single focus on sharing waters in terms of volumetric allocations to the sharing of multiple benefits derived from more optimal water arrangements within basins. This suggests that future transboundary water governance frameworks need to include a 'future politics' of synergised 
decision-making that adopts a broad and integrative approach to regional integration and socio-economic growth (GWP, 2010). Central to this is the long-term policy challenge of linking processes of regional economic cooperation to countrylevel and/or basin-level water management and vice versa (GWP, 2010). This implies that close attention should be paid to the importance of not only integrating disciplines but also integrating different levels of scale for more effective holistic management (Pollard and Du Toit, 2008). Greater emphasis has therefore been placed on the exploration of new and alternative approaches to the way we govern our natural resources at the transboundary level.

Various scholars have contributed to the scientific epistemic community's awareness of the importance of integrated approaches, transdisciplinarity and holistic water management (Arthington et al., 1992; Arthington, 1998; Swales and Harris, 1995; King et al., 2003; King and Brown, 2006; Pollard and Du Toit, 2008). These scholars have diverse disciplinary backgrounds, but are largely from the natural sciences, and have advocated a range of integrative models at either the national or the project level. However, very little of this groundbreaking work has been scaled up to the regional level. Moreover, while research efforts over many decades of research have focused on the role of 'the team' in enabling holistic analyses, the role of the individual has received less attention. In particular, the role of young water professionals, not least in rising to the challenges of these complex issues, has been nebulous.

This paper builds on the existing literature on transdisciplinarity and its different conceptualisations in relation to water in Southern Africa. Firstly, it interrogates the role of water in regional socio-economic development in the SADC region. In this regard, it transcends political borders to examine the role of water in the broader development discourse and its inherent linkages with people, space, power, and knowledge. Secondly, it acknowledges the well-documented argument that disciplinary borders have to be transcended in order to address complex challenges, but also examines the need for transdisciplinary responses to regional socio-economic development and transboundary water challenges. The traditional approach to transboundary water governance is examined through a complexity lens. Thirdly, this paper strives to make a valuable contribution to knowledge in that it attempts to take the transdisciplinary discourse beyond 'the team' model to examine the role of the individual and the internalisation of transdisciplinarity as a mindset beyond collective models. In this regard, the paper emphasises the need for 'transdisciplinary individuals' to deal more competently with the complexities of regional integration, and particularly, the role of the young professional in rising to this challenge.

\section{Beyond political borders: the role of water in regional socio-economic development in SADC}

The water resources of the SADC region are highly sensitive and complex to understand, govern, effectively use and fairly distribute. This reality is created by many overlapping factors. Firstly, the SADC region contains 21 international river basins to which one or more SADC member states are riparian, which results in complex hydrological linkages across national borders within the SADC region on the mainland (Turton and Ashton, 2008). Thus, water is fundamentally a shared resource in our region.

Secondly, some of the most economically developed Southern African states, such as South Africa and Botswana, have limited water resources, which may constrain future

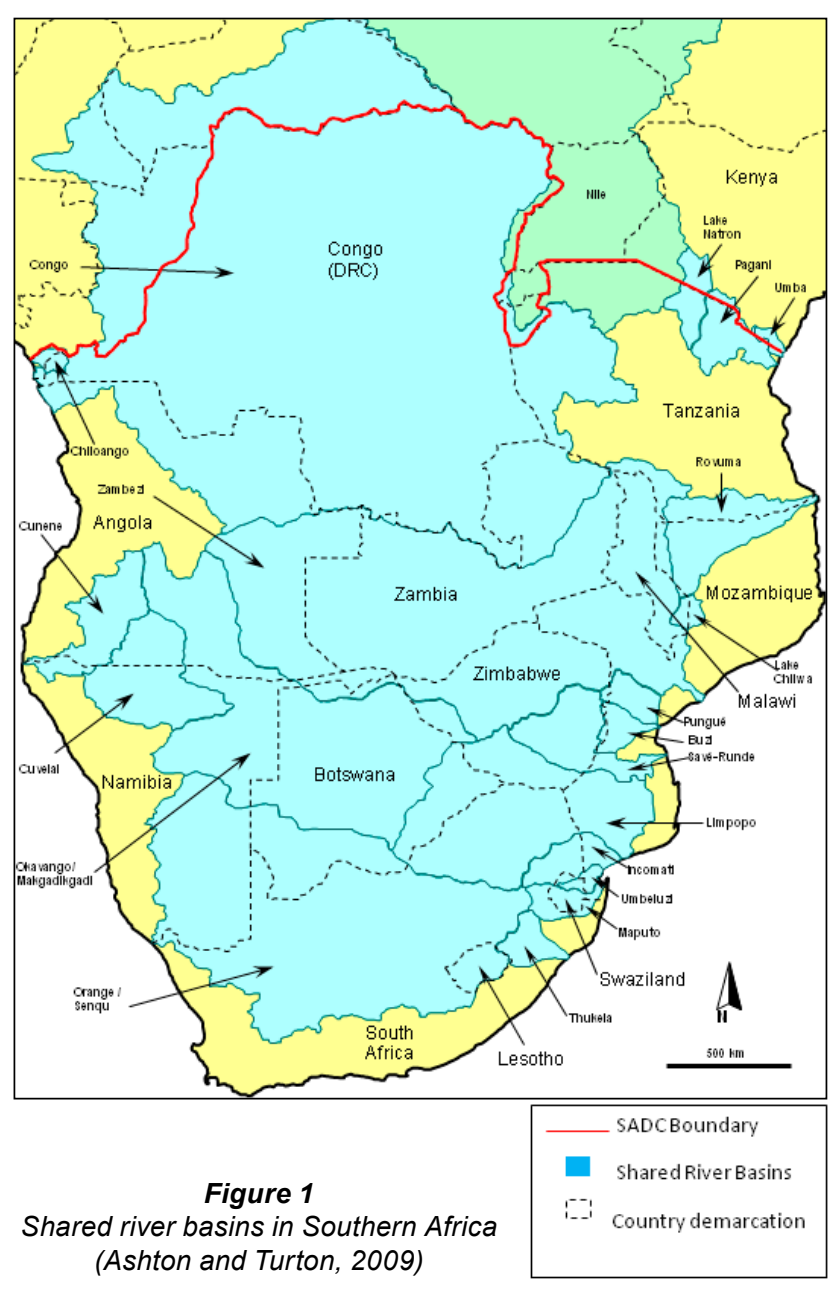

economic development (Turton, 2003; 2008; Turton and Ashton, 2008; Ashton et al., 2008).

Thirdly, a spatial development pattern exists where several key cities or centres of economic development (such as Johannesburg, Pretoria, Harare, Bulawayo, Francistown, Gaborone and Windhoek) are not located on rivers, lakes or seafronts, but instead have been built on or near watersheds or continental divides (a continental divide is defined as the line following the 'height of land,' or the drainage divide on a continent such that the drainage basin on one side of the divide feeds into one ocean or sea, and the basin on the other side either feeds into a different ocean or sea, or else is endorheic) (Oberholster and Ashton, 2008; Turton, 2008; Turton et al., 2008). This has resulted in the dependency of these cities on water that has to be pumped uphill, which subsequently causes severe sewage return flows as these rivers are additionally burdened with transporting waste material, most of which enters downstream water storage reservoirs (Oberholster and Ashton, 2008).

Fourthly, there are pronounced developmental differences within the SADC region rendering some countries more effective than others at mobilising necessary human, financial and technological resources to address water scarcity and related human-welfare needs.

Finally, the SADC region is confronted with numerous social challenges, such as population growth, urbanisation, climate change, refugee movements, and outbreaks of disease which impact on water needs and use. This makes it imperative that demands on this finite resource are managed carefully to 


Figure 2
Conceptual
illustration of the
primary processes
and causal
linkages between
water, energy,
food security and
development
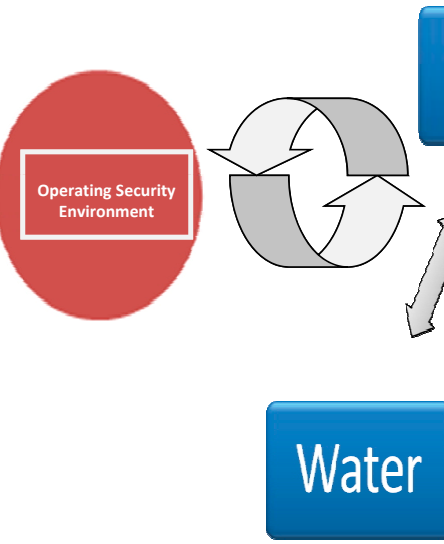

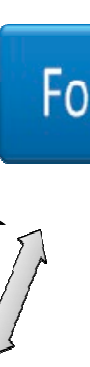

Food

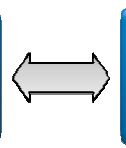

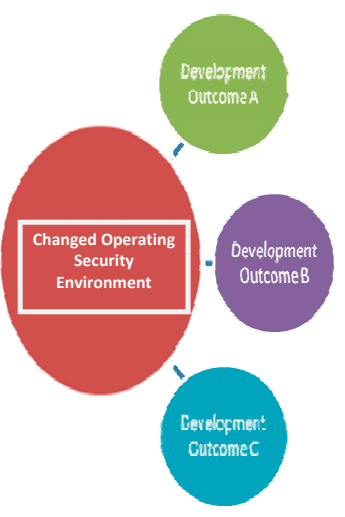

Energy ensure its availability, at an affordable price and good quality, to existing and future generations.

All these issues will affect and be affected by the way in which transboundary waters are managed. Thus, 'governance issues form the central obstruction to sound and equitable water sharing and management' (UN, 2006: 12).

Similarly, not only does integrated and cooperative governance of transboundary waters contribute substantially to the socio-economic development of the riparian countries, it also promotes regional and sub-regional cooperation for economic integration in Southern Africa. Indeed, international river basins are increasingly important as development drivers in Southern Africa. Their huge resource potential in agriculture, energy production and other sectors is well known. Many of the potential benefits that can derive from increased cooperation have been documented and frameworks designed to improve decision-making on how to turn cooperation into positive development outcomes. However, major barriers still exist to exploiting these development opportunities (Granit and Claassen, 2009). These barriers could be political (e.g. political instability); policy-orientated (e.g. uncoordinated trade negotiations of SADC countries with the European Union); social (e.g. mass immigration into South Africa); economic (e.g. access to finance); technical (e.g. lack of technical capacity); or operational (e.g. poor maintenance of infrastructure). Other barriers are linked to the increasing institutional complexity between shared basins and regional economic integration. Overlapping institutions at the regional level and the multiplicity and changing nature of 'memberships' by nation states ensures that river basins are part of an increasingly complex landscape of institutions, policies, trading relations and sectoral demands. The relevance of the existing institutional complexity presents challenges but also opportunities for sectors that are directly or indirectly involved with water issues to increasingly integrate in terms of decision-making in agriculture, energy, industry and urban development in particular. Response strategies for vulnerable areas and communities that take such analyses into account prove to paint more holistic and integrated pictures of the socio-political landscape in which development takes place.

Despite these and many other inherent interlinkages, transboundary water management has not featured as an integral part of the economic integration discourse until now. Traditionally, water, energy and/or food security have been addressed in silo approaches paying little, if any, attention to the fact that power generation requires water input and that power is required for purification, transport, and distribution of potable water, and that both these resources directly influence food security. These interlinkages and synergies are often overlooked when policy-makers devise partial responses to individual problems. Successful policies and plans depend on having decision-makers who understand the complexities of the problem to which the policy tries to respond. The intuitive way of designing policy (which tends to be issue-specific and somewhat reductionist), is often unable to achieve desired outcomes given the inter-related dependencies and complexities of any issue. Thus, any successful policy development and implementation process demands a detailed understanding of complex and interrelated problems (GWP, 2010). Young's examination of the linkages between environmental regime effectiveness and 'fit' and 'scale', is also applicable in this regard (Young, 2002). Addressing water challenges at the 'wrong' level and conceptualised as 'simple' cause-and-effect relations undermines the effectiveness and legitimacy of water policies (Young, 2002).

In addition, complex regional challenges cannot be solved by individual countries acting in isolation (GWP, 2010). On the contrary, sometimes they can be exacerbated when countries act in this manner. For example, a country like Malawi obtains most of its electricity from hydropower plants on the Shire River, an outlet of Lake Malawi which flows into the Zambezi River. However, Malawi's hydropower supply is greatly influenced by the flood season in the Zambezi River, into which the Shire River flows. When the Zambezi is in flood, the large volume of water pushes water back up into the smaller Shire River. This effectively slows down power generation along the Shire. Further pressure on streamflow as a result of excessive flooding may actually bring the power-generation process to a standstill. The problem is at its worst when floodgates at the Kariba Dam, far upstream on the Zambezi, are opened. That said, however, controlled release of that water is necessary for both flood control and to avoid damage to the dam. Inter-state coordination and the joint management of water supply and power generation are therefore critically important. This example illustrates the need for states to collaborate in order to maximise the benefits of development options, and also demonstrates that silo approaches to resource management not only produce sub-optimal deployment of resources, but could negatively affect other resources that are closely related.

Indeed, the importance of scale (spatial and temporal) is critical to our understanding of transboundary water governance and the solutions we propose. Depending on the most appropriate level of scale, different capacities are therefore required. At the regional economic community (REC) level, for 
instance, there is a need for a system level analysis and outlook. Specifically, there is need to understand the role of transboundary waters in promoting regional integration by providing valuable services such as energy production; primary products; industry and domestic water use; and ecosystem services. An important discussion to have in this regard relates to the type of institutions that are most appropriate to deal with this reality. Are water-centric institutions such as river-basin organisations in fact the most appropriate vehicles through which to channel development strategies? Water-centric institutions do not (and should not) operate in a vacuum. They are an important piece (one of many) of the puzzle in dealing with natural resource governance and development but will have to work with other sectors and multi-level institutions to address root causes of problems and issues.

\section{Beyond disciplinary borders: the need for transdisciplinary responses to regional development and transboundary water governance}

\section{A summary of transdisciplinarity in the water sector over 3 decades}

Despite these inherent linkages and the common logic of managing shared resources in an integrated way, traditionally and historically the water sector's approach to problem-solving, socio-economic development and overall water management has been segmented. In South Africa, this has led to a high degree of technical and scientific innovation and expertise in the sector. Since the 1980s, however, this model and related mindset started to change (King et al., 2003).

Over time, it became widely recognised by South African academics and researchers that the existing natural resource management approaches were not adequately addressing the complex nature of challenges and rapidly changing systems (Gunderson et al., 1995; Holling, 2000; Kinzig et al., 2000; Holling, 2001; Folke et al., 2002; Holling et al., 2002; Pollard and $\mathrm{Du}$ Toit, 2008). This redirected focus on integrated approaches was echoed in the emergence of concepts such as INRM (Thomas, 2002; Sayer and Campbell, 2004) and IWRM (Görgens et al., 1998; GWP-TAC, 2000 Penning de Vries et al., 2002; King et al., 2003; King and Brown, 2006).

Various other scientific methodologies were developed in the 1990s, including the Building Block Methodology (BBM) developed in South Africa (King and Louw, 1998), the Holistic Approach (Arthington et al., 1992; Arthington, 1998) and the Expert Panel Assessment Method (Swales and Harris, 1995) developed in Australia, and the Downstream Response to Improved Flow Transition or DRIFT (King et al., 2003) developed in South Africa, to advise on water requirements for the maintenance of the entire ecosystem (King et al., 2003; King and Brown, 2006). These methodologies purported that:

- All major abiotic and biotic components constitute the ecosystem to be managed

- The full spectrum of flows and their temporal and spatial variability constitute the flows to be managed (King et al., 2003; King and Brown, 2006)

Additionally, they relied on 2 assumptions. Firstly, holistic approaches required the collective technical inputs from biophysical scientists in disciplines ranging from hydrology,

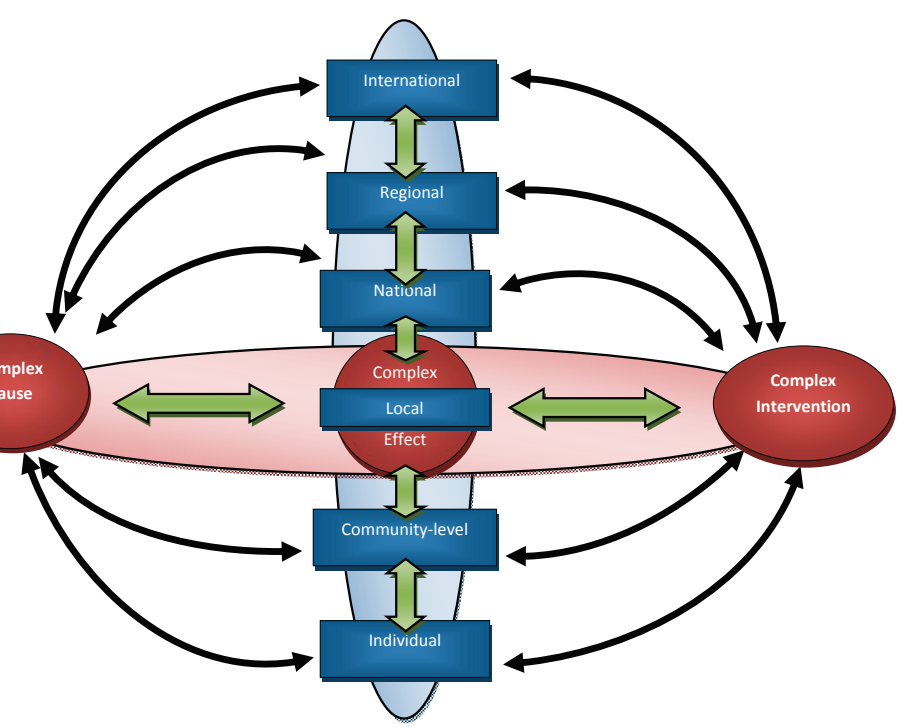

Figure 3

Diagrammatic illustration of relationship between complex problems and scale

hydraulics, fluvial geomorphology, sedimentology, chemistry, botany to zoology. As such, they were highly technical in nature and outcome. Secondly, these holistic approaches necessitated a high degree of expertise or 'deep' knowledge. Experienced specialists employed discipline-specific methods to further an understanding of flow-ecosystem relationships, and then collaborated with other team members, within the overarching process of the holistic approach, to reach consensus on environmental flows (King et al., 2003). However, apart from being highly prescriptive in nature, these approaches did not sufficiently address the impacts of river changes on subsistence users (King et al., 2003). While DRIFT did attempt to integrate the latter through the production of biophysical and socio-economic scenarios, the incorporation of social science specialists into investigations was limited to investigations of subsistence users. Moreover, with the exception of a few studies (see King et al., 2003 for an example of DRIFT's applicability to the Lesotho Highlands Water Project), holistic approaches focused mainly on the national, sub-national (catchment) or project-specific levels, with very little scaling up to the regional or beyond national levels of scale. Their effectiveness at understanding the role that water plays in regional integration efforts, or how holistic approaches can be applied to high-level policy frameworks, is therefore less obvious. The disconnect between levels of scale is noteworthy.

Given the nature of complex water problems - regional in origin but predominantly local in their effects - these approaches have been highly effective in addressing the local effects of a complex problem but less so in addressing the origin of the problem itself. In large part, this outcome is the result of the prescriptive and targeted nature of holistic approaches. As illustrated in Fig. 3, complex problems are comprised of complex causes and complex effects that in turn require complex interventions. The relationship between cause, effect and intervention is closely linked to the issue of scale and indeed can influence several levels simultaneously. Interventions that fail to capture the multi-levelled nature of the problem and how it intersects with different levels of scale produce sub-optimal strategies that are unable to be scaled up or down for broader applicability. Woodhill (2010) articulates 
3 main reasons why enhanced local and regional action is important. Firstly, it is the scale at which much directed action needs to be taken and coordinated. Secondly, it is through activities at the local or regional level that individuals can engage in a meaningful debate about complex water problems. And finally, it is at the regional and local levels that counterbalancing and political opposition to the power of purely economic interests, global corporations, or the state, have to be mobilised (Woodhill, 2010).

Traditionally then, the water sector has been dominated by 'technical experts'. The development of integrated approaches and methodologies therefore gave impetus to a new thinking in the management of water based on integrative and collective expertise. However, both the pre-1980 scientific thinking and the subsequent integrated approaches were founded on sound empirical, technically-driven expertise embedded within a positivist tradition. In this regard, they have relied heavily on notions of objectivity, quantification, accuracy, linearity, and rationality. In many ways this positivist science, sometimes referred to as 'hard science', has been seen as the preferred and most reliable type of knowledge to base decisions on regarding water management, thus reinforcing the natural and technical science preponderance.

\section{Problematising the mainstream response through complexity lenses}

Positivist science is particularly useful when trying to answer questions that can be understood through reductionism. Issues that can be understood in this manner behave in a deterministic and predictable way and are not influenced by normative issues. However, it should be noted that most issues and problems in the water sector are complex and inseparable from normative, ethical and subjective realities (Audouin et al., 2011). These norms are rooted in locally specific contexts, practices, institutions and beliefs. Positivist science is unable to deal with and respond to these latter issues that invariably creep into any research or problem-solving process.

Also, Cilliers (1998; 2001) points out that complex systems are open and made up of elements that are inter-connected. If we wish to gain a comprehensive understanding of such a system, we need to understand, not only the system itself, but also the environment to which it is connected. This interconnected environment needs to be seen as a whole and not studied in an atomistic or 'broken up' manner (Pollard and Du Toit, 2008). Atomistic understandings run the risk of losing the essence of the whole. Put simply, complexity thinking dictates that socioeconomic development needs to be seen as an integrated whole. To separate river management from water's link to energy, poverty alleviation and so on, is to lose some of the essence of the entire socio-economic development project. To separate water in one country from its transboundary implications in another is to underestimate the complexity of the river. To study water or sustainable development only from a natural science or engineering viewpoint runs the risk of losing sight of the profound social, cultural, spiritual, political facets of water and economic development (Berkes et al., 2003).

Whilst positivist science clearly has an important role to play in facilitating an understanding around problems facing socio-economic development and related water management, it is unable to take cognizance of and respond to the unpredictability, non-linearity, value-based, context-bound nature of many water problems we are faced with today (Berkes et al., 2003; Pollard and Du Toit, 2008). In this regard, complexity thinking is a critical tool to responding holistically to complex problems. In contrast to traditional scientific methods that rely on principles of reduction and disjunction, the logic of complexity requires our knowledge generation and problem-solving interventions to include seemingly antagonistic, contradictory and complementary strategies (Audouin et al., 2011). The study of complex challenges in the water sector requires that the logic of complexity is implemented and applied in practice. Transdisciplinary, cross-cutting research programmes, and interventions are believed to be some of the most promising ways of implementing the inclusive, problem-solving way of 'knowing and doing,' which we are called upon in complexity thinking (Audouin et al., 2011).

Given this realisation, there has been a well-documented and growing recognition of the need for more transdisciplinary responses to the challenges facing the water sector. However, the positivist tradition in which modern science and reality (as we know it) are embedded has produced several limiting consequences to advancing a truly transdisciplinary mindset. Firstly, it has resulted in the construction of governance 'silos', that is to say, the development of separate governmental departments of energy, mining, and water. Natural resources are therefore governed in separate and often isolated sectors. Secondly, it has resulted in the formation of legal and institutional 'silos' - separate legal and institutional frameworks to govern these sectors. For example, policy formulation for any one particular natural resource often (but not always) occurs with very little coordination with and inclusion of its linkages with other resources. If a certain policy does manage to give attention to linkages with other resources in its text, the manner in which this policy is implemented becomes counter-intuitive because of the way in which sectors are structured - one department usually has the mandate to implement a particular policy with little coordination with other departments during the implementation stages. Thirdly, the positivist tradition has resulted in the development of knowledge 'silos' - separate specialists that have acquired domain-specific expertise to study any one of these issues, often in isolation.

All of these consequences of the positivist tradition have contributed to the development of a 'separate sector' reality. This has even led some scholars to point out the inherent tension in the use of the term, 'water sector,' as this can similarly promote a silo-based approach to water management rather than encouraging an understanding of water as fundamentally linked to all sectors (Dent, 2011). All sectors engage in the phenomenon of water just as all sectors engage in the realm of water (Dent, 2011). The notion of a separate sector being responsible for water therefore negates the concept of coresponsibility, co-management, co-operation, and co-ordination (Dent, 2011). Similarly, it perpetuates an 'us' and 'them' syndrome and fosters finger-pointing and blaming (Dent, 2011). However, this does not detract from the fact that a water sector does exist in the minds of many stakeholders; that extensive resources have been pooled to improve this sector; and that scientists have dedicated lifetimes to serving this very sector. To ignore the sector's existence, or to call it by another name, obscures the incremental change needed to integrate it with other sectors as a first step. Stakeholders in the water sector should, therefore, not lose sight of the sector's positionality in how it responds to complex challenges involving water and how it interacts with stakeholders outside of the sector. Moreover, they should acknowledge the sector and cautiously work with it in order to maintain buy-in and to circumvent sectoral sensitivities. 
The societal response to the 'silo' paradigm has therefore been to perpetuate this reality by creating 'silo' teaching of university curricula; a lack of social scientists involved in socalled 'technical issues'; funding agendas that tend to favour natural science methodology and thus support less social science research; an organisational bias favouring natural scientists and technical experts in research organisations; and highlevel political decision-makers relying on technical experts for the information they need (Jacobs and Nienaber, 2011) .

This is tied to the (mis)perception that 'hard science' is more accurate and valuable than the 'soft' and often qualitative science of social scientists. Despite these challenges, there is growing recognition of the need for social scientists equipped with skills, understanding and passion for governance issues in the water sector. A social science presence is important as social scientists have unique expertise in cultural, behavioural and societal realities. This equips them with the skills to interpret subjective, objective, inter-subjective and structural aspects of society. This aids understanding of the social developments, needs and drawbacks of a context. Also, social science has a familiarity with institutional capacity-building mechanisms and thus can offer critical support to the bodies and individuals that are mandated to manage water in the region. Furthermore, a primary goal of social science is to influence public policy by general practical knowledge that can assist policymakers to make informed decisions and in so doing foster more effective policy and governance options (Jacobs and Nienaber, 2011).

In summary, transdisciplinary science has the added challenge of being embedded within a world that is dominated by a positivist tradition underpinning the way we think, act, and structure our governance systems. Conducting transdisciplinary research to address complex regional water challenges requires us to acknowledge this duality. On the one hand, the sector acknowledges that the game has changed significantly; on the other hand, longstanding practices, understandings and ways of doing things remain influential.

\section{Beyond transdisciplinary teams: the need for 'transdisciplinary' individuals}

\section{An overview of transdisciplinarity}

If complexity thinking is the vehicle through which to achieve truly integrative approaches, transdisciplinarity is the fuel to get us there. Transdisciplinarity is more than a new discipline or supra-discipline - it is a different manner of seeing the world, and one that is more systemic and more holistic than before. In so doing, it extends enquiry through various levels of reality and organisations. The transdisciplinary approach facilitates a deeper understanding of complexity and complex problems by examining the different facets of reality through the lens of multiple perceptions. This is only possible through the collaboration of multiple actors, and through acknowledging positionality and different knowledge forms. Transdisciplinarity therefore transcends the notion of a new and innovative research methodology in the sense that it is more than a way of conducting research, but rather the 'position' or 'approach' a scientist takes in his or her thinking and positionality regarding problem-solving (Jacobs and Nienaber, 2011).

It should be noted that this view of transdisciplinarity has been conceptualised in a range of disciplines by various scholars. Given the widespread interest in the term, there is also a certain degree of inconsistency about how closely related terms like multidisciplinarity and transdisciplinarity are. Some authors will, for example, refer to multidisciplinarity when describing the same features that are given by authors writing about transdisciplinarity. The authors note this overlap of terminology in the literature but specifically subscribe to Max-Neef's (2005) definitions in which he suggests that multidisciplinarity occurs when a group of experts belonging to various disciplines collaborate on a project or initiative and produce an outcome that will deal with an issue in terms of many different angles but will not necessarily fit together comfortably as a synthesised whole. There is growing endorsement of the importance of creating multidisciplinary teams to deal with complex problems. Whilst such teams are quite widespread, few are able to move beyond multidisciplinary understandings towards more inclusive and coherent transdisciplinary synthesis.

Max-Neef (2005) suggests that there are 2 ways of understanding the concept transdisciplinarity. There is the so-called 'weak' and 'strong' version of the concept. Weak transdisciplinarity functions as described in Fig. 4. An action can be considered transdisciplinary when there is evidence of more than one block being present on each of the levels shown. Thus, 'weak' transdisciplinarity is seen as a method supporting transdisciplinary work which calls on a large number of different actors to answer various types of questions when grappling with a complex problem (Jacobs and Nienaber, 2011).

In contrast, strong transdisciplinarity is more than just a method to systematically solve complex and changing problems. It is a unique positionality and approach to science and problem-solving. Transdisciplinarity, in this case, calls on individuals to grapple with the limitations of binary, linear and rationalist logic that dominates the scientific world. This implies the recognition of multiple subjective realities, accessible through different levels of perception. Moreover, there is permeability between these different levels of reality which allows for links to be formed between them. Within this system of complex interlinkages there is likely to be a variety of tensions and contradictions, but also complementarities, between the whole and the parts of a system, and between the observer and the observed. By maximising the leverage that this multi-level approach allows, individuals are required to be constantly reflexive about their positionality, the subjective perceptions they hold, their world views, and their belief systems (Jacobs and Nienaber, 2011). In essence, strong transdisciplinarity requires an internalisation of this thinking within the individual, beyond, but in synergistic alignment with, the collective understandings of teams. The primary unit of analysis, in this case, is the individual, and the manner in which he/she is able to adopt an individualised understanding of transdisciplinarity (Jacobs and Nienaber, 2011; MaxNeef, 2005).

This being said, part of the challenge of adopting a transdisciplinary perspective and way of operating is that it is difficult to know how to start. It is in many ways a project that resists formalisation and clear criteria which can be adhered to in order to achieve its goals. However, when sifting through the body of literature on this topic a number of key features of transdisciplinarity can be identified. These 6 criteria can be used as a broad guide when applying a transdisciplinary approach to problem-solving, and can also be used as a set of goals for those aspiring to achieve transdisciplinary practice:

\section{- Interlinked levels of reality}

This is about acknowledging that there are different levels 


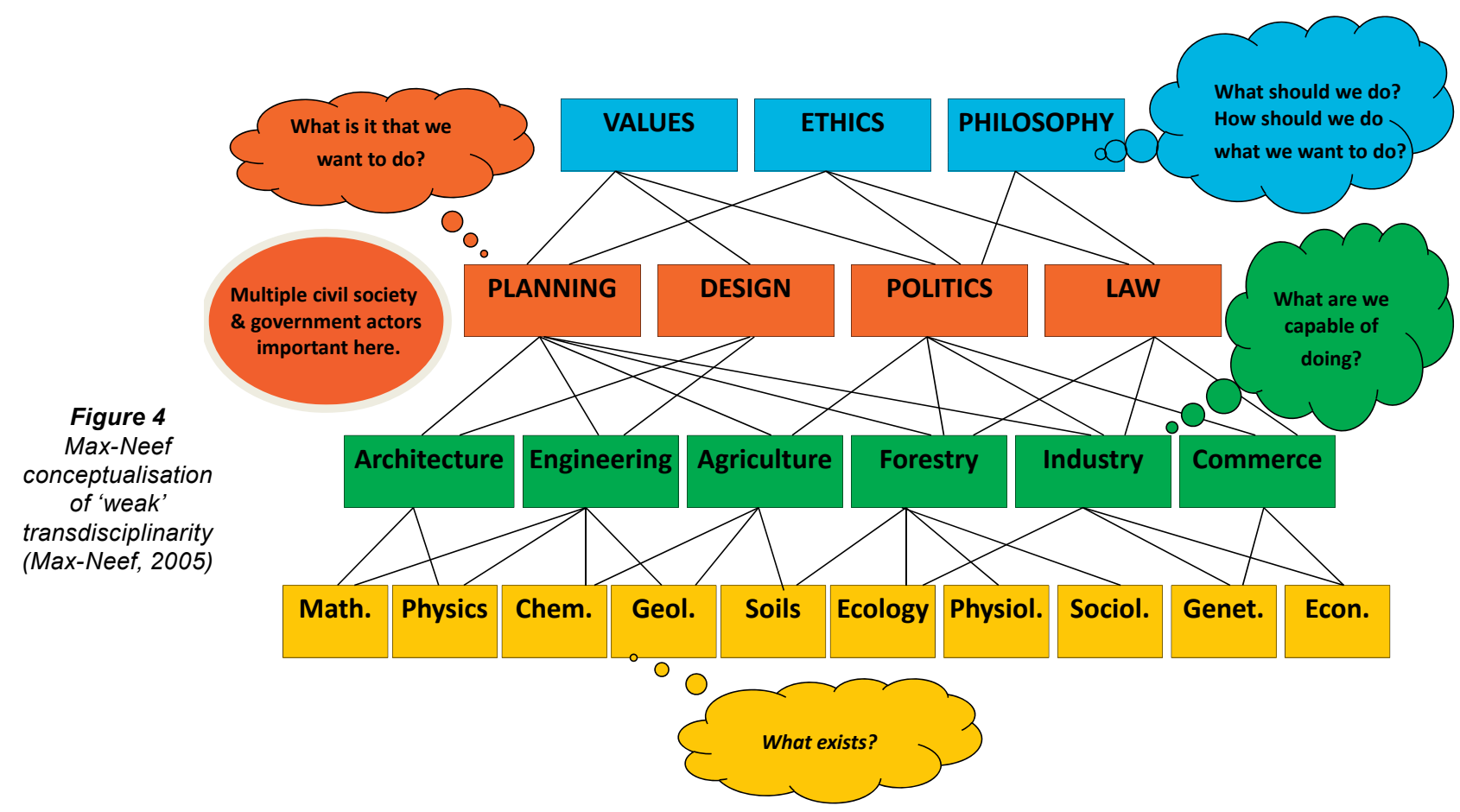

and perspectives of reality. The objective and the subjective, natural and social systems all constantly intersect. There is the perspective of individuals, of communities, of experts, of politicians, of nature itself as a silent stakeholder; which all interact and intersect with each other. Reality occurs at different levels of scale, in different places and times. Also, these levels of reality are consumed by relativity as no level of reality is complete on its own. The picture is only made complete by the multiple and often incomprehensible connections to other levels of reality and perspectives (Nicolescu, 2005).

\section{- Different types and forms of information}

There are many different types of information. Information can be empirical (answering 'what exists?' questions), pragmatic (answering 'what are we capable of doing?' questions) and ethical or normative (answering 'what do we want to do and what should we be doing for the benefit of future generations?' questions) (Max-Neef, 2005). There are also different forms in which knowledge can emerge. It can be formally written or passed through a set of universally accepted rules; it can be written but only subject to local, context-specific issues; it can be undocumented and contained in people's memories and experiences; it can come from experts, cultural practices, ordinary citizens, and so on (Fabricius et al., 2006; Audouin et al., 2011).

\section{- Knowledge produced by multiple actors}

Knowledge production needs to occur through an inclusive process that includes multiple actors. These actors can include a variety of experts belonging to various disciplines, actors from civil society, actors from government, holders of lay knowledge, interested end-users and so on (Luks and Siebenhuner, 2007; Funke et al., 2011). It is this intercommunicative process between different actors that helps to produce knowledge that is relevant to end-users, appropriate to the problem at hand, and trusted by endusers (Lawrence and Depres, 2004; Russel et al., 2008). Knowledge that takes account of the normative questions When acting or doing research in a transdisciplinary manner it is impossible to avoid coming up against normative or value-based issues. This is because every person is consciously and unconsciously shaped by a value system. Thus, knowledge does not exist in isolation from the social, political and cultural context in which it is used and produced. Choices will always have to be made that cannot be backed up scientifically (e.g. the range of issues to be addressed as identified by stakeholders, the purpose of the study which can be influenced by the nature of the funding agency, political imperatives or the strategic priorities of the research institutes involved and the skills, time, budget and data, available to the study) (Luks and Siebenhuner, 2007).

\section{- Acknowledging complexity}

Acknowledging complexity involves the recognition that complex problems are made up of multiple non-linear, interconnected parts (Lawrence and Depres, 2004;

Nicolescu, 2005). It is often the connections between these parts that make it unique. Thus complexity cautions against breaking complex challenges or ideas into small parts as this can result in losing the essence of or changing the very thing being studied. Thus problems need to be faced as holistically as possible, rather than in a fragmented process. This applies both to the process of research, but also to practice (Cilliers, 1998; 2001). Silo approaches to dealing with development are unlikely to succeed as they try to compartmentalise a complex issue that can only be dealt with in an integrated and holistic manner.

\section{- Context-specific and bounded knowledge}

The transdisciplinary approach deeply accounts for specific contexts. This means that intrinsic to understanding, researching or responding to a given problem is the need to understand the specificities of the area in which the issue is situated. This is about understanding the culture, people, history, politics, social dynamics, biophysical specificities and so on of a certain area as these factors shape and are part of the issue (Lawrence and Depres, 2004; HorlickJones and Sime, 2004; Funke et al., 2011). 
Whilst it is clearly a huge undertaking to move towards a more transdisciplinary paradigm it is increasingly important to rise to this challenge. Russel et al. (2008) cite 3 crucial reasons for the growing need for transdisciplinary responses. Firstly, they point out that knowledge innovation and services are increasingly central to economic growth. The type of knowledge that is in demand is that which has practical application and has been produced in partnerships. This knowledge needs to be trusted and 'owned' by end-users. In order for this trust to emerge, knowledge essentially needs to be socially robust which implies that it needs to have context relevance, support from a wide range of stakeholders and be able to fit into the normative terrain of the context to which it will be applied (Gibbons, 1999). Given the particular demands of the increasingly influential knowledge market, it is necessary to use transdisciplinarity to respond to this demand. Secondly, there is a growing concern about the state of the environment. It is increasingly recognised that knowledge that can contribute to environmental sustainability needs to be able to deal with the complex interconnections between the social and natural environments. Thus it is imperative for actors from different disciplines (social and natural sciences) as well as actors from other sectors with different realities and different matters of concern to come together in a transdisciplinary manner to respond to environmental challenges appropriately. Thirdly, the general public is increasingly engaged in their own information-gathering and monitoring activities. This is resulting in a public that is both ever more dependent on knowledge but also more sceptical about it. Thus, it is important to draw the public and end-users into knowledge production and problemsolving processes to gain their input and trust of the knowledge that is produced. These criteria are therefore both applicable to transdisciplinary team contexts, but also are invaluable to individuals such as high-level policy-makers influencing the regional water policy landscape.

\section{The role of the 'transdisciplinary individual' in facilitating regional integration and development}

The importance of individuals and politics to the success or failure of effective water governance in Southern Africa is under-researched despite being critically important. Swatuk argues that water governance in Southern Africa exists within a context of differently empowered actors who negotiate and renegotiate roles and rights to resources (Swatuk, 2002; 2005). This may have positive consequences (a close-knit community of technical experts based on trusting relationships, a wealth of knowledge and experience in the water sector) and negative consequences (power asymmetries and an elite epistemic community, and institutional memory loss when these individuals leave their employment as alluded to previously). These individuals have succeeded in persuading their constituencies of the moral appropriateness of specific codes of conduct relating to transboundary water governance. In essence, key individuals have played a significant role in shaping standards of behaviour, and best practice regarding transboundary water governance in Southern Africa (Jacobs, 2010). The clarity with which policies, legal and institutional frameworks are drafted, is therefore influenced by an individual dimension. That is to say, key individuals play a major role in the framing of policy debates, best practice in governance structures and priority areas for policy, the way in which they are codified, and the degree of socialisation in terms of influencing others' uptake of these norms, beliefs and principles (Jacobs, 2010).

A significant opportunity to accelerate development from a water perspective in this regard is the need to train leaders that can speak different (technically-specific) languages. This speaks both to the importance of transdisciplinarity and the use of multidisciplinary teams to better understand the interlinkages of resources, as well as the role and need for individuals who are able to adopt a broader and more holistic mindset indicative of Max-Neef's (2005) 'strong' transdisciplinarity. Advancing this debate may include the identification of particular personality types or personality profiles for transboundary managers.

It is, however, important to emphasise that the need for 'transdisciplinary individuals' in no way renders the role of the 'transdisciplinary team' null and void. On the contrary, they are both essential if the origin as well as the effects of complex problems are to be addressed. Additionally, there will always be some individuals who are more prone to embracing this 'transdisciplinary profile' as described above and others who are more prone to achieving depth and specificity in their research, and whose expertise will be invaluable in transdisciplinary team contexts. The two are not mutually exclusive. Both are therefore needed to advance specific objectives within transdisciplinary governance for regional economic development.

Whilst an enormous amount of work has been done to identify what transdisciplinarity is and how to create transdisciplinary teams, less consideration (within the literature on transdisciplinarity) has been given to the idea of what it means to internalise the transdisciplinary perspective on an individual level. How does one identify, train or become a transdisciplinary person? This is a necessary 'next step' as ultimately the transdisciplinary team is only as strong as the individual team member's capacity to understand and internalise the complextransdisciplinary logic. Given the identified 'key features' of transdisciplinarity, it is clear that a number of traits in an individual are crucial to being able to internalise the transdisciplinary perspective.

Firstly, this individual needs to be able to build networks within the domain of the 'unfamiliar'. Essentially this has 2 facets to it. It is necessary to learn to build and collaborate with people beyond one's own discipline/sector/department/country. This is often done by building transdisciplinary teams with a goal of producing integrated knowledge and co-producing knowledge. End-users, impacted groups and interested parties need to be given the chance to participate, advise, co-define the problem and contribute their own knowledge (which is often different to so-called scientific knowledge). Building diverse networks is about social scientists collaborating with natural scientists, government working with researchers, researchers partnering with civil society and local communities. This is invariably a process that requires patience, trust-building and willingness to step out of one's comfort zone (Giri, 2002). These diverse networks also act as sources of information. The availability of reliable, comparable and relevant data across the region remains a key constraint to effective planning and development. This ranges from biophysical data on surface and groundwater resources to social and economic data that should be key criteria for selecting the best development options. The ability of individuals to source different kinds of data from different sources proves invaluable in facilitating decision-making at the regional level.

This individual also needs to be able to sustain these 
networks across space and time. The need for diverse and complex networking has been recognised and endorsed by the SADC Water Division at regional level. This division, amongst other activities, hosts a variety of events that promote dialogue amongst players in water governance and regional development. A prominent example is the annual SADC MultiStakeholder Water Dialogue. This activity is promoted by the Water Division's Regional Strategic Action Plan. Since 2007 this Dialogue has been used as a platform for regional stakeholders to discuss and share experiences. The overall theme of these talks is focused on 'watering' development within the SADC region and highlighting how IWRM approaches can address key aspects of socio-economic development and poverty reduction in Southern Africa. The Dialogue is crosssectoral in nature and promotes the view that 'water is everyone's business.' It aims to bring together the resource keepers, users of the resource and those who make influential decisions that have an impact on the resource both positive and negative, but who may not necessarily form part of the immediate water sector (SADC, 2011).

Secondly, the transdisciplinary individual needs the capacity to engage in meaningful dialogue as this is the mechanism that unlocks the opportunity to understand, co-create and build networks. Indeed, Scharmer's Theory-U-inspired model is noteworthy here to describe how emerging leaders should innovate across sectors (Scharmer, 2009). Scharmer (2009) argues that meaningful dialogue occurs at multiple levels of scale and at different phases of project implementation in different ways, but starts with 'deep listening' to all key players. Such dialogue requires that you 'suspend (your) own point of view as the only point of view and recognise that there are multiple equally important points of view to be expressed'. By releasing defensiveness about your own viewpoint emergent synthesis can arise (Giri, 2002). Dialogue also needs to happen in a manner that is sensitive to power relations. If one actor is perceived to be powerful, other people in the conversation may feel too intimidated to speak. This dynamic needs to be carefully managed to foster fruitful dialogue. This point is of critical importance to policy-makers operating at the regional level as a result of the inherent power asymmetries due to a region's geopolitics, with some countries being more able to influence policy decisions because of socio-economic clout, military hegemony, human capacity, and/or influential alliance. Alleviating power asymmetries requires, amongst other things, the development of a regional community of interest around water and regional integration efforts (Jacobs, 2010). The SADC region has been particularly successful at fostering this through policy harmonisation in the water sector. The challenge is now to link these processes to regional integration activities such as trade and economic development to reduce economic power asymmetries and to increase regional harmonisation. At the regional project-level, when defining transboundary governance projects, we need to be cognizant of sectoral boundaries and try to facilitate cross-sectoral learning as a means to bridge this divide. Mechanisms for effective dialogue should be developed and implemented. These can range from the participative development of shared visions, to objectives and strategies and decisions on which development options to jointly pursue. Such dialogue should extend from the highest political levels, through to technical and private sector involvement to communities and individuals. The dialogue should also cut across horizontally to bring together different sectors and disciplines. Such joint action will create a fertile environment for the effective implementation of results from other areas of development support.
Thirdly, it is important for the transdisciplinary individual to be embedded within their own discipline, sector and context from which they operate. Embeddedness firstly entails that the individual recognises the multitude of perspectives, assumptions, possible contradictions and lack of homogeneity in his/her own discipline, sector, and context (Giri, 2002). Embeddedness also requires that the individual understands his/her own context in relation to other contexts, people and actors. How are you different? How are you similar? Where can you build synergies with other disciplines or sectors and other actors? Also, by being deeply rooted within a specific discipline and/or sectoral viewpoint it should become less threatening to move beyond one's own context. This enables the individual to understand, incorporate and collaborate with others as his/her own training continues to be a deep part of learning and experience even if for a while it is necessary to draw on the perspectives of a different discipline or actor to effectively solve a problem. In practice, people involved with managing water are regularly faced with the issue of being embedded in one discipline and context, but forced to face issues outside of their 'comfort zone'. A government scientist, for example, who makes recommendations about groundwater flows, will find their fairly technical work of groundwater monitoring being pulled into more social and political issues when faced with questions like: What are the social impacts of polluted groundwater? What are the transboundary implications of groundwater use? Who is responsible for dealing with the repercussions of polluted groundwater? Such complex questions necessitate talking to representatives from the mining industry, the private sector, activists, land-owners, local communities, river-basin organisations, various provincial governments and so on. This is not the 'traditional' realm of a groundwater expert but a realm that is necessary to engage in, in order to understand and deal with problems appropriately (Hobbes, 2010).

The issue of embeddedness of individuals is also important to consider, as one of the common criticisms of transdisciplinarity is that disciplinary depth (years of experience and deep knowledge acquisition in a specific field) is sacrificed. One loses track of one's own discipline and struggles to find time to prioritise 'deep' knowledge acquisition if too much time is spent trying to work with people of other disciplines or sectors. However, we suggest that the loss of disciplinary depth is not directly linked to a pursuit of transdisciplinarity because of the ongoing importance of embedding oneself within a discipline. Instead, different people tend to gravitate towards different mechanisms of building their careers. Some feel the desire to pursue commitment to a narrow set of disciplinary goals and 'depth' in a specific issue, whilst others are energised by more generalist ways of building their careers. Both routes are necessary components of building holistic responses to problems. The challenge is to be able to identify when one or the other is needed in specific situations. Indeed, the development of highlevel policy decisions at the regional level necessitates individual policy-makers to have a broad knowledge and experience with a range of sectors, development opportunities and national contexts in order to be able to identify linkages that can facilitate regional cooperation.

Fourthly, this transdisciplinary person needs to have a powerful societal conscience and awareness because ultimately transdisciplinarity is about grappling with the ethical question of what 'ought to be done' for the benefit of future generations (Max-Neef, 2005). Thus any person who internalises a transdisciplinary perspective will have internalised the idea that their actions need to move beyond the self and be focused 
on issues pertaining to broader societal benefit. Thus, individuals need to balance their own personal career aspirations and desires with awareness that what they do now needs to contribute to a long-term picture of growth and sustainability for all. For example, the need for ethical and socially conscious citizens and experts has been strongly articulated over the last 20 years by hydrosolidarity proponents. Part of the hydrosolidarity vision is the belief that in order to balance delicate upstream and downstream asymmetries in rivers, to ensure long-term ecosystem sustainability, and to balance the complex links between water and other activities, it is essential to have a generation of conscious, caring and aware 'hydrocitizens'.

Fifthly, the transdisciplinary individual needs to be able to think in a complex, interlinked manner and deeply relate to the logic of complexity. Scharmer (2009) refers to a similar concept of 'shared seeing and sensing' of the current situation and of emerging future possibilities. This requires all stakeholders to see themselves as part of the whole (Scharmer, 2009). Thus this person sees fragmentation of knowledge as inappropriate, sees knowledge production and reality as being defined by hybrid, non-linear, reflexive phenomena that are interconnected in a complex manner. In addition, local contexts are intrinsically important to understanding any phenomenon or solving any problem (Lawrence and Depres, 2004).This implies that the transdisciplinary individual is able to identify issue-specific, sectoral, country, and other scale-related linkages despite the hierarchical and silo-based structure of departments, i.e. how local contexts influence and are influenced by national, regional and international contexts, how various sectors are directly and indirectly connected, etc. It also implies that the transdisciplinary individual has a diverse network and is able to bring the 'right people' together at the right time. These characteristics point to the importance of context and the role it plays in decisions and behaviour.

Finally, the transdisciplinary individual needs to have a modest positionality (Cilliers, 2001; 2005). This is about admitting that given the complexity of the world and the problems we try to address in relation to regional economic growth, it is impossible to ever perfectly solve or understand an issue completely. The pursuit of knowledge is always imperfect. Similarly, there is never a perfect solution to a problem. Policymakers need to acknowledge this frailty within the context of their work at the regional level.

Most importantly, the transdisciplinary individual recognises the co-existence of a governance framework embedded in the positivist tradition and the sectoral awareness of the complexity of water-related problems in the region. By adopting a flexible approach, the transdisciplinary individual is able to constantly oscillate between these 2 paradigms producing iterative, 'learning-by-doing' methods of advancing water's role in regional economic integration and development.

\section{The role of young water professionals in taking up the transdisciplinary challenge}

We therefore need people who can embrace this individual transdisciplinary challenge (Scharmer, 2009). One of the challenges facing all sectors in Southern Africa is the reality that many of the experts are fast approaching retirement age. Indeed, there has also been an exodus of skills out of Southern Africa in recent years due to an array of factors ranging from increases in crime, to lack of confidence in the government, and social mobility. The transnational mobility of highly skilled people is recognised; however, there are considerable variations in occupational mobility patterns. Water specialists in African countries often emigrate to apply their trade in developed countries, but also move to international and multi-national organisations. Similarly, South Africa attracts significant capacity, particularly from Zimbabwe, where highly skilled people seek economic security. Essentially, this means that the 'faces' of the water sector move around a lot as they are drawn to various opportunities to develop their careers (Dent, 2010). For the water sector the repercussions of this reality include high staff turnover; the loss of skills and institutional memory due to the departure of experienced staff; little or no career path and succession planning; the appointment of non-technical personnel to management positions requiring technical experience; as well as the absence of well-structured educational and training programmes suitably targeted to all stakeholders in the water management chain. These factors impact institutional effectiveness as it involves a large degree of re-learning and rebuilding of trusting relationships. However, this problem is not unique to South Africa with neighbouring states experiencing the same challenges. When experienced staff members leave the sector or reach retirement age, institutional memory loss occurs, with younger staff not being able to fill their shoes fast enough. A 2006 Water Research Commission (WRC) report concluded that institutional memory loss results in negative impacts on service delivery and opportunities for co-operation, particularly where mechanisms to institutionalise individuals' knowledge have not been put in place (Pegram et al., 2006).

Part of the perceived reason for the high degree of skills flight, is that the older generation of professionals (known as the baby-boomer generation) is the largest generation of active workers yet and thus there are more people leaving the workplace than entering it to replace them (Glass, 2007). Thus the future of the water sector strongly depends on an incoming generation of relatively young people to rise to existing and emerging problems. Given this reality it is important to consider the capacity of this generation of young water professionals to rise to the challenge of the transdisciplinary individual. The younger working professional is either part of Generation $\mathrm{X}$ which, depending on which authors' dates are used, falls broadly between 1965 and 1981, or part of the Millennial Generation, that is the group of people who were born between 1982 and 2002. Extensive research has been done over the years on the characteristics of different generations and how this impacts on their interests, expectations, capacity and views of the world (Glass, 2007). Whilst the importance of understanding the individual and his or her specific traits remains important, it is useful to refer to this generational literature to gauge generally what we can expect from the younger generations and how this relates to the water sector, how they can contribute, what they need, and how they should be educated in preparation for the day when they have to fill the shoes of older and more experienced professionals.

Children of Generation $\mathrm{X}$ are also often referred to as the 'latchkey kids' as they were the first generation to experience having both parents working outside of the home. They tend to be quite cynical about government as they have seen some of the mistakes government has made during their lifetimes. Company loyalty is not a top priority for this generation as they tend to be quite entrepreneurial and individualistic. This generation is efficient, likes flexible working hours and learning opportunities. They are comfortable with technology although not on the same level as the Millennial Generation (Alch, 2000; Howe and Strauss, 2003, as cited in Muntz, 2004; Gursoy et al., 2008; Glass, 2007). As a general rule, Millennials have been 
raised by ever-present parents and teachers who have guided and supported their development and choices throughout their lives. Thus this is a generation who is at ease with mentoring, expectations, support and supervision. They highly value mentoring and feedback in the workplace. This generation tends to be confident and they have great expectations of themselves and others. They are free thinking but tend to have a preference for teamwork. They enjoy challenges, want structure to their day and desire respect from early on in their careers. This generation favours a high-tech environment. This trait is particularly distinct amongst Millennials as they are the first generation to have been born into a technology or digital age of computers, internet, cell phones and related technology. Given this exposure to technology Millennials tend to be at ease when linked into technology-based networks and are socially aware given the ease with which they can be updated about world events. This generation does tend to have difficulty thinking deeply about issues, perhaps due to their over-abundant access to information which is hard to sift through and prioritise. They also tend to struggle to create their own deadlines, priorities and plans in their lives given the prominent role that their parents have played in doing this for them when they were younger (Alch, 2000; Howe and Strauss, 2003, as cited in Muntz, 2004; Gursoy, et al., 2008; Glass, 2007; Donnison, 2010).
In Table 1 the discussed traits of an ideal transdisciplinary person and the traits of the younger working generations are combined in an attempt to detect some of the challenges and opportunities that this generation faces in rising to the challenge of becoming transdisciplinary people. Given that young professionals possess a unique skills set, institutions can leverage this by building workplaces that foster open communication and learning, participative leadership and quality of life. Secondly, clearly defined functions, roles and responsibilities as well as succession plans should be put in place to ensure that knowledge is transferred in a sustainable manner. Thirdly, employers need to identify how different generations operate in a professional environment as well as the unique characteristics they offer an organisation.

\section{Acknowledging the limits to transdisciplinarity at the regional level}

While it has been argued that the role of the transdisciplinary individual in furthering an understanding of complex waterrelated issues in regional integration efforts is significant, it is also important to acknowledge the difficulties in finding and/ or grooming individuals that are predisposed to adopting this mindset.

Additionally, while the key features of transdisciplinarity have been outlined above, and guidelines provided for how

\begin{tabular}{|c|c|c|}
\hline \multicolumn{3}{|c|}{$\begin{array}{l}\text { Table } 1 \\
\text { Key challenges and opportunities facing younger working professionals when developing the skills needed to be a } \\
\text { 'transdisciplinary person' }\end{array}$} \\
\hline $\begin{array}{l}\text { Traits of a transdisciplinary } \\
\text { person }\end{array}$ & The capacity of younger working professionals to rise to the transdisciplinary challenge & \\
\hline \multirow{2}{*}{$\begin{array}{l}\text { Able to build networks and } \\
\text { work in teams within the } \\
\text { domain of the 'unfamiliar' }\end{array}$} & $\begin{array}{l}\text { - Open to change, new technologies } \\
\text { - At ease with technology which facilitates networking } \\
\text { - Like to work in a flexible manner } \\
\text { - Accustomed to being 'linked in' all the time } \\
\text { - Enjoy constant feedback which wide networks can facilitate } \\
\text { - Team oriented }\end{array}$ & PROS \\
\hline & $\begin{array}{l}\text { - Are used to having their time structured and being told what to do which means that they } \\
\text { struggle when there is no one to advise in unfamiliar terrain } \\
\text { - Technology-based networks (which young professionals are generally skilled with) cannot } \\
\text { replace meaningful face-to-face contact } \\
\text { - May struggle to communicate with people from older generations given the stark genera- } \\
\text { tional differences }\end{array}$ & CONS \\
\hline \multirow{2}{*}{$\begin{array}{l}\text { Capacity to engage in } \\
\text { meaningful dialogue }\end{array}$} & $\begin{array}{l}\text { - Confident and thus not afraid to engage in dialogue } \\
\text { - Able to engage in dialogue using various technologies (Skype, Twitter, etc.) }\end{array}$ & PROS \\
\hline & \begin{tabular}{|l} 
- Communication skills are perhaps not adequately developed given over-dependence on \\
technology-based communication (Skype, e-mail, chat, Facebook, blogs, etc.)
\end{tabular} & CONS \\
\hline \multirow{2}{*}{$\begin{array}{l}\text { Embeddedness of one's } \\
\text { own discipline }\end{array}$} & $\begin{array}{l}\text { - These are 'big picture' individuals given their exposure to an array of world issues and } \\
\text { flexible approach to building degree programmes. }\end{array}$ & PROS \\
\hline & $\begin{array}{l}\text { - This generation has grown up in a truly globalised era, and is faced with more multiplicity } \\
\text { and diversity than any other generation before. This may make focusing and embedding } \\
\text { oneself in a particular area of expertise a difficult choice to commit to. }\end{array}$ & CONS \\
\hline \multirow[b]{2}{*}{ Societal conscience } & $\begin{array}{l}\text { - A highly socially aware generation - tend to be socially conscious and wish to serve a } \\
\text { community }\end{array}$ & PROS \\
\hline & $\begin{array}{l}\text { - Tend to experience major social upheaval from a distance, i.e. via live streaming, } \\
\text { photographs, blogs, and Twitter. Thus awareness of social issues does not necessarily come } \\
\text { in a personalised form given the distance from the actual context that technology creates. }\end{array}$ & CONS \\
\hline \multirow{2}{*}{$\begin{array}{l}\text { Able to think in an complex } \\
\text { interlinked manner }\end{array}$} & - At ease with multitasking & PROS \\
\hline & - Bombarded with so much information - deep thinking skills are often sacrificed & CONS \\
\hline \multirow[t]{2}{*}{ Modest positionality } & $\begin{array}{l}\text { - Has seen world events (terrorist attacks, tsunamis, climate change) and how difficult these } \\
\text { problems are to deal with - modesty imposed by societal experience }\end{array}$ & PROS \\
\hline & - Tend to be over-confident and think of themselves as 'achievers' & CONS \\
\hline
\end{tabular}


individuals can internalise a transdisciplinary mindset, it is difficult to operationalise a skills set that individuals should have. The bold career moves required to obtain a diverse portfolio are daunting, particularly given the scepticism with which high staff turnover and 'jumping jobs' are received. However, it should be borne in mind that even when we are able to step outside of our comfort zones and overcome the initial fear of adopting a transdisciplinary mindset, having a wide range of experiences on a résumé does not constitute the automatic predisposition to being a transdisciplinary individual.

One of the most significant challenges to transdisciplinarity is that it takes its toll on individuals. Firstly, the need for multiple perspectives and inputs is a time-consuming process, requiring much patience and perseverance. Additionally, project budgets are rarely designed to include transdisciplinary processes. As such, there are few resources committed to incentivise integrative activities. And given the time commitment and personal interaction time required, individuals may find it frustrating to work in this environment. The understaffed and over-capacitated SADC Water Division is a good example of how taxing it can be for the few staff members employed in this capacity to work in a cross-sectoral and cross-country domain; not only do they have to represent the region at national conferences in all member countries, but they also have to coordinate regional and international activities. Transdisciplinarity should therefore not be viewed as a onedimensional tool to 'fix things'. Moreover, transdisciplinary projects produce complex interventions and outcomes, which are time-consuming to implement.

\section{Conclusions}

This paper has presented a case for transdisciplinarity, not only as a supra-discipline, but also as a methodology and a way of seeing the world. Specifically, it attempted to scale up the relevance of the transdisciplinary discourse to the regional level to examine the role of water in regional socio-economic development and integration efforts. These are complex issues that need to be addressed in an integrated and transdisciplinary manner..

Secondly, the importance of individuals to the success or failure of specific regional water-governance projects was emphasised. As such, the paper examined the role of individuals in internalising transdisciplinarity. The role and generational characteristics of young water professionals was interrogated. In many ways, young water professionals are strategically placed to take up the challenge of transdisciplinarity in the water sector in the future, but need to be groomed in order to be able to effectively address the complexity of waterrelated problems. The role of the individual in relation to the transdisciplinary project has been analysed in several disciplinary-specific analyses, such as education sciences. However, more research needs to be conducted on the role of the individual in actively addressing complex water-related challenges, in redefining the manner in which multiple sectors cooperate around these issues, and ultimately influencing the direction of socio-economic development at the regional level.

Global change necessitates the exploration of new and alternative approaches to the way we govern natural resources. This requires us to look at issues of water governance from a multilevel lens, one which emphasises the multiplicity of actors, scale, power, knowledge and agency. Very importantly, it necessitates transdisciplinarity as an appropriate research channel through which to address new and emerging challenges and complexities, such as climate change, increasing water scarcity, loss of skills and social inequality.

\section{Acknowledgements}

We would like to express our sincere gratitude to the South African Water Research Commission (WRC) for their very supportive role in the establishment of the Young Scholars Forum (YSF) in Transboundary Water Governance, which is the initiative that has enabled this research. The WRC's support of this initiative is a clear indication of the growing recognition, by institutions in the water sector, of the need to build capacity in transdisciplinarity in order to foster a sector that is equipped to respond to the complex water-security challenges we are faced with today and tomorrow. We also acknowledge the support of the Water Institute of Southern Africa (WISA) and the International Water Association (IWA) for opening up their networks. In particular, we would like to recognise the central role of the South African Young Water Professionals (SA YWP) in providing the support base, the membership, the vision, instrumentality, and the many hands that have made this initiative the success that it is. The leverage displayed by the SA YWP network in terms of its provision of broad coverage to ensure uptake of transdisciplinarity proves that SA YWP is certainly a key player and sector leader in representing young water professionals.

\section{References}

ALCH ML (2000) The echo-boom generation: A growing force in American society. The Futurist 34 (5) 42.

AUDOUIN M, PREISER R, NIENABER S, DOWNSBOROGH L, LANZ J and MAVENGAHAMA S (2011) Exploring the Logic of Complexity for Researching Social-Ecological Systems. Internal Report to the National Research Foundation (NRF), Akili Young Scientists Initiative. NRF, Pretoria, South Africa.

ARTHINGTON AH (1998) Comparative evaluation of environmental flow assessment techniques: Review of holistic methodologies. LWRRDC Occasional Paper 26/98. LWRRDC, Canberra, Australia.

ARTHINGTON AH, BUNN SE, PUSEY BJ, BLUHDORN DR, KING JM, DAY JA, THARME RE and O'KEEFFE JH (1992) Development of an holistic approach for assessing environmental flow requirements of riverine ecosystems. In: Pigram JJ and Hooper BP (eds.) Proc. International Seminar and Workshop on Water Allocation for the Environment. November 1991, Armidale, Australia. The Centre for Water Policy Research, University of New England.

ASHTON PJ, HARDWICK D and BREEN C (2008) Changes in water availability and demand within South Africa's shared river basins as determinants of regional social and ecological resilience. In: Burns MJ and Weaver AvB (eds.) Exploring Sustainability Science: A Southern African Perspective. Stellenbosch University Press, Stellenbosch, South Africa.

ASHTON PJ and TURTON AR (2009) Water and security in SubSaharan Africa: Emerging concepts and their implications for effective water resource management in the southern African region (Chapter 55). In: Brauch HG, Spring UO, Grin J, Mesjasz C, Kameri-Mboti P, Behera NC, Chourou B and Krummenacher H (eds.) Facing Global Environmental Change: Environmental, Human, Energy, Food, Health and Water Security Concepts. Hexagon Series on Human and Environmental Security and Peace, Volume IV. Springer-Verlag, Berlin. ISBN: 978-3-540-68487-9. 661-674.

BERKES F, COLDING J and FOLKE C (2003) Navigating SocialEcological Systems. Cambridge University Press, Cambridge, UK.

CILLIERS P (1998) Complexity and Postmodernism: Understanding Complex System. Routledge, London, New York. 
CILLIERS P (2001) Boundaries, hierarchies and networks in complex systems. Int. J. Innovat. Manage. 5 (2) 135-147.

CILLIERS P (2005) Knowledge, limits and boundaries. Futures 37 605-613.

DENT M (2010) Absorptive capacity is imperative for IWRM implementation. CMA Leadership Letter 110 (28 November 2010). URL: http://ses.ukzn.ac.za/Libraries/CMA/CMA_Leadership Letters $110-115$. sflb.ashx.

DENT M (2011) Personal communication, 24 September 2011. Senior Lecturer, School of Environmental Sciences, University of KwaZulu-Natal. Private Bag X01, Scottsville 3209, RSA.

DONNISON S (2010) Unpacking the Millennials: a cautionary tale for teacher education. Aust. J. Teach. Educ. 32 (3) 1-13.

FABRICIUS C, SCHOLES R, and CUNDILL J (2006) Mobilising knowledge of integrated ecosystem assessments. In: Reid WV, Berkes F, Wilbanks T and Capistrano D (eds.) Bridging Scales and Knowledge Systems. pp. 165-184.

FOLKE C, CARPENTER S, ELMQVIST T, GUNDERSON L, HOLLING CS and WALKER B (2002) Resilience and sustainable development building adaptive capacity in a world of transformations. Ambio 31 437-440.

FUNKE N, NIENABER S and HENWOOD R (2011) Scientists as lobbyists? How can science make itself heard in the South African policy-making arena. J. Public Aff. 10 421-432.

GIRI AK (2002) The calling of a creative transdisciplinarity. Futures 34 103-115.

GIBBONS M (1999) Science's new social contract with society. Nature 402 11-18

GLASS A (2007) Understanding generation differences for competitive success. Ind. Commer. Train. 39 (2) 98-103.

GWP-TAC (GLOBAL WATER PARTNERSHIP, TECHNICAL ADVISORY COMMITTEE) (2000) Integrated water resources management. Background paper No 4, Global Water Partnership Technical Advisory Committee, Stockholm, Sweden. ISBN: 91-630-9229-8. $71 \mathrm{pp}$.

GWP (GLOBAL WATER PARTNERSHIP) (2010) The 2010 GWP Consulting Partners $(C P)$ Meeting with the theme: Exploring the Role of Water Security in Regional Economic Development. Presentation by Technical Committee Chair, Mohamed Ait Kadi, at the CP meeting held in Stockholm, Sweden, 3-4 September 2010

GÖRGENS A, PEGRAM G, UYS M, GROBICKI A, LOOTS L, TANNER A and BENGU R (1998) Guidelines for Catchment Management to Achieve Integrated Water Resources Management in South Africa. WRC Report No. KV 108/98. Water Research Commission (WRC), Pretoria, South Africa.

GRANIT J and CLAASSEN M (2009) A path towards realising tangible benefits in transboundary river basins. In: Jagerskög A and Zeitoun M (eds.) Getting Transboundary Water Right: Theory and Practice for Effective Cooperation. Report No. 25, SIWI, Stockholm, Sweden. pp. 21-26. URL: http://www.google.co.za/url? $\underline{\mathrm{sa}=}=\mathrm{t} \&$ source $=$ web \&ct $=$ res \&cd $=1 \&$ ved $=0$ CBQOFjAA\&url $=h t t p \% 3$ A $\% 2 F \% 2 F w w w . s i w i . o r g \% 2 F d o c u m e n t s \% 2 F R e s o u r c e s \% 2 F R e p o r t$ s\%2FReport 25 Transboundary Waters with WWW.pdf\&rct=j\&$\mathrm{q}=\mathrm{SIWI}+$ report $+25 \& \mathrm{ei}=$ OPP9S7rIOJLu0 $\mathrm{wSkxKnxDO \& usg=AFOj}$ CNFLEdxZocOv-47NcdBwbd0de2D9vw

GUNDERSON LH, HOLLING CS and LIGHT SS (1995) Barriers and Bridges to the Renewal of Ecosystems and Institutions. Columbia University Press, New York.

GURSOY D, MAIER TA, and CHI CG (2008) Generational differences: an examination of work values and generational gaps in the hospitality work force. Int. J. Hosp. Manage. 27 (1) 448-458.

HOBBES P (2010) Personal communication, 2 June 2010. CSIR Senior Scientist. CSIR, PO Box 395, Pretoria, 0001.

HOLLING CS (2000) Theories for sustainable futures. Conserv. Ecol. 4 (2) Art. 7. URL: http://www.ecologyandsociety.org/vol4/iss2/ art7l.

HOLLING CS (2001) Understanding the complexity of economic, ecological and social systems. Ecosystems 4 390-405.

HOLLING CS, GUNDERSON LH, and LUDWIG D (2002) In quest of a theory of adaptive change. In: Gunderson LH and Holling CS (eds.) Panarchy: Understanding Transformations in Human and Natural Systems. Island Press, Washington D.C. 3-22.
HORLICK-JONES T and SIME J (2004) Living on the border: Knowledge, risk, and transdisciplinarity. Futures 36 441-456.

HOWE N and STRAUSS W (2003) Millennials go to College: Strategies for a New Generation on Campus. American Association of Collegiate Registrars and Admissions Officers, Washington DC

JACOBS IM (2010) Norms and Transboundary Co-Operation in Africa: The Cases of the Orange-Senqu and Nile Rivers. Ph.D. Dissertation, University of St. Andrews, St. Andrews, Scotland. JACOBS IM and NIENABER S (2011) Incentivising Young Social Science Perspectives in the SADC Water Sector: Building a Forum for Young Scholars in Transboundary Water Governance. WRC Report No. TT 487/11. Water Research Commission, Pretoria, South Africa. ISBN: 978-1-4312-0104-4.

KING JM and LOUW D (1998) Instream flow assessments for regulated rivers in South Africa using the Building Block Methodology. Aquat. Ecosyst. Health Restoration 1 109-124.

KING J, BROWN C and SABET H (2003) A scenario-based holistic approach to environmental flow assessments for rivers. River Res. Applic. 19 619-639.

KING J and BROWN C (2006) Environmental flows: Striking the balance between development and resource protection. J. Ecol. Soc. 11 (2) Art. 26. URL: http://www.ecologyandsociety.org/vol11/iss2/ $\underline{\operatorname{art} 26 /}$

KINZIG PA, CARPENTER S, DOVE M, HEAL G, LEVIN S, LUBCHENCO J, SCHNEIDER SH and STARRETT S (2000) Nature and Society: An Imperative for Integrated Environmental Research. NSF Workshop Report, 5-8 June, Tempe, Arizona, November 2000. URL: http://www.public.asu.edu/ akinzig/nsfes. pdf (Accessed 23 September 2011). 69 pp.

LAWRENCE RJ and DEPRES C (2004) Introduction: Futures of transdisciplinarity. Futures 36 397-405.

LUKS F and SIEBENHUNER B (2007) Transdisciplinarity for social learning? The contribution of the German socio-ecological research initiative to sustainability governance. Ecol. Econ. 63 418-426.

MAX-NEEF MA (2005) Foundations of transdisciplinarity. Ecol. Econ. 53 5-16

MUNTZ P (2004) Millennials go to college. J. Coll. Admission. April 1, 2004. URL: http://findarticles.com/p/articles/mi qa3955/ is 200404/ai n9383887/.

NICOLESCU B (2005) Transdisciplinarity - Past, Present and Future. Centro de educacao transdisciplinar (CETRANS). URL: www. cetrans.com.br (Accessed 23 September 2011).

OBERHOLSTER P and ASHTON P (2008) State of the Nation Report: An Overview of the Current Status of Water Quality and Eutrophication in South African Rivers and Reservoirs. Parliamentary Grant Deliverable. Council for Scientific and Industrial Research, Pretoria, South Africa.

PEGRAM G, MAZIBUKO G, HOLLINGWORTH B and ANDERSON E (2006) Strategic Review of Current and Emerging Governance Systems Related to Water in the Environment in South Africa. WRC Report No. 1514/1/06. Water Research Commission, Pretoria, South Africa.

PENNING DE VRIES FWT, ACQUAY H, MOLDEN D, SCHERR SJ, VALENTIN C and COFIE O (2002) Integrated Land and Water Management for Food and Environmental Security. Comprehensive Assessment Secretariat, Global Environment Facility, International Water Management Institute (IWMI), Colombo, Sri Lanka.

POLLARD S and DU TOIT D (2008) Integrated water resource management in complex systems: How the catchment management strategies seek to achieve sustainability and equity in water resources in South Africa. Water SA 34 (6) 671-679.

RUSSEL AW, WICKSON F and CAREW A (2008) Transdisciplinarity: Context, contradictions and capacity. Futures 40 460-572.

SCHARMER CO (2009) Leadership development is not about filling a gap but about igniting a field of inspired connection and action: Ten propositions on transforming the current leadership development paradigm. Paper prepared for: Round Table Meeting on Leadership for Development Impact. The World Bank, The World Bank Institute, Washington, D.C. September 27- 28, 2009, Draft 1.1 (revised 5 October, 2009). 
SADC (SOUTHERN AFRICAN DEVELOPMENT COMMUNITY) (2011) Information note. Proc. $5^{\text {th }}$ SADC Multi Stakeholder Dialogue 2011. URL: http://www.icp-confluence-sadc.org/sites/ default/files/SADC\%20Dialogue\%202011\%20Documentation.pdf.

SAYER JA and CAMPBELL B (2004) The Science of Sustainable Development: Local Livelihoods and the Global Environment. Cambridge University Press, Cambridge, UK. ISBN: 0-521-82728-0.

SENGE P, SMITH B, KRUSCHWITZ N, LAUR J and SCHLEY S (2008) The Necessary Revolution: How Individuals and Organizations are Working Together to Create a Sustainable World. Nicholas Brealey Publishing, London, UK.

SWALES S and HARRIS JH (1995) The Expert Panel Assessment Method (EPAM): A new tool for determining environmental flows in regulated rivers. In: Harper DM and Ferguson AJD (eds.) The Ecological Basis for River Management. John Wiley \& Sons, New York.

SWATUK L (2002) The new water architecture in Southern Africa: Reflections on current trends in the light of 'Rio+10'. Int. Aff. 78 (3) 507-530.

SWATUK L (2005) Political challenges to implementing IWRM in Southern Africa. Phys. Chem. Earth 30 872-880.

THOMAS RJ (2002) Revisiting the conceptual framework: Project sites and results of assessment methodology 97 for INRM developed in Penang and Cali. In: Turkelboom F, LaRovere R, Hageman J, El-Khartib R and Jazeh K (eds.) Proc. $4^{\text {th }}$ INRM Workshop:
Putting INRM into Action, 16-19 September, 2002, ICARDA, Aleppo, Syria.

TURTON A (2003) The hydropolitical dynamics of cooperation in Southern Africa: A strategic perspective on institutional development in international river basins. In: Turton A, Ashton $\mathrm{P}$ and Cloete T (eds.) Transboundary Rivers, Sovereignty and Development: Hydropolitical Drivers in the Okavango River Basin. AWIRU and Green Cross International, Pretoria and Geneva.

TURTON A (2008) A South African perspective on a possible benefitsharing approach for transboundary waters in the SADC region. Water Alternatives 1 180-200.

TURTON A and ASHTON P (2008) Basin closure and issues of scale: The Southern African hydropolitical complex. Int. J. Water Resour. Dev. 24 305-318.

TURTON A, PATRICK MJ and RASCHER J (2008) Setting the scene: Hydropolitics and the development of the South African economy. Int. J. Water Resour. Dev. (Special Edition) 24 319-323.

UNITED NATIONS (UN) (2006) Water a Shared Responsibility. UN World Water Development Report 2. UNESCO, France and Berghahn Books, New York

WOODHILL J (2010) Sustainability, social learning and the democratic imperative: Lessons from the Australian landcare movement (Chapter 4). In: Blackmore C (ed.) Social Learning Systems and Communities of Practice. The Open University, UK.

YOUNG OR (2002) The Institutional Dimensions of Environmental Change: Fit, Interplay, and Scale. MIT Press, Cambridge, MA. 